\title{
RESEARCHPAPER
}

\section{Citric acid production from pre-treated sugarcane bagasse by Aspergillus niger under solid state fermentation}

\author{
ABHISHEK SHARAN ${ }^{1 *}$, AMIT ALEXANDER CHARAN ${ }^{2}$, AKHILESH BIND ${ }^{1}$ AND SHASHI BHUSAN \\ TIWARI ${ }^{1}$
}

\author{
${ }^{1}$ Department of Biochemistry and Biochemical Engineering, Sam Higginbottom Institute of Agriculture, Technology \\ and Sciences, ALLAHABAD (U.P.) INDIA \\ ${ }^{2}$ Department of Molecular and Cellular Engineering, Sam Higginbottom Institute of Agriculture, Technology and \\ Sciences, ALLAHABAD (U.P.) INDIA \\ Email : abhsharan@rediffmail.com
}

Article Info :Received : 15.08.2015; Revised : 30.08.2015; Accepted : 15.09.2015

Citric acid is one of the important commercially produced organic acid. The aim of the present work was to study the utilization of pre-treated sugar cane bagasse for citric acid production using Aspergillus niger under solid state fermentation. The maximum value of citric acid was observed in acid treated substrate followed by urea and heat respectively. Fermentation conditions were also optimized and maximum production of citric acid occurred when the $\mathrm{pH}$, Initial moisture content and temperature of the fermentation medium were 5,65 per cent and $30^{\circ} \mathrm{C}$, respectively. As a globally required organic acid for various industrial applications, citric acid can be produced at large scale by utilizing pre-treated agro residues such as sugarcane bagasse. Application of agro residues in the production of value added product can be a positive step towards agricultural waste management.

Key words : Citric acid, Aspergillus niger, Pre- treatment, Solid state fermentation

How to cite this paper: Sharan, Abhishek, Charan, Amit Alexander, Bind, Akhilesh and Tiwari, Shashi Bhusan (2015). Citric acid production from pre-treated sugarcane bagasse by Aspergillus niger under solid state fermentation. Asian J. Bio. Sci., 10 (2) : $162-166$. 